\title{
Oxidative decolorization of a malachite green oxalate dye through the photochemical advanced oxidation processes
}

\author{
Ghime D., Goru P., Ojha S. and Ghosh P.* \\ Department of Chemical Engineering, National Institute of Technology, Raipur, 492010, CG, India \\ Received: 23/12/2018, Accepted: 18/02/2019, Available online: 26/02/2019 \\ *to whom all correspondence should be addressed: e-mail: prabirg.che@nitrr.ac.in
}

https://doi.org/10.30955/gnj.003000

\section{Abstract}

This report was aimed at an investigation of efficiency for Photochemical Advanced Oxidation Processes (UV photolysis, $\mathrm{UV} / \mathrm{H}_{2} \mathrm{O}_{2}, \quad \mathrm{UV} / \mathrm{TiO}_{2}, \mathrm{UV} / \mathrm{H}_{2} \mathrm{O}_{2} / \mathrm{TiO}_{2}$ and $\mathrm{UV} / \mathrm{H}_{2} \mathrm{O}_{2} / \mathrm{Fe}^{2+}$ processes) to decolorize Malachite Green Oxalate (MGO) dye. Experimental runs were performed using laboratory scale photochemical reactor. About $98 \%$ decolorization was obtained with initial 100 ppm MGO dye in Photo-Fenton process under optimal conditions (60 ppm Fe ${ }^{2+}$ concentration, $12 \mathrm{mM}$ of oxidant concentration, at $\mathrm{pH} 3.0$ for $60 \mathrm{~min}$ ). $97 \%$ decolorization was obtained using $\mathrm{UV} / \mathrm{H}_{2} \mathrm{O}_{2} / \mathrm{TiO}_{2}$ process having $\left[\mathrm{TiO}_{2}\right]$ of $0.6 \mathrm{gm} / \mathrm{L}$ for similar reaction conditions. The percentage decolorization of $\mathrm{MGO}$ was in range of $94-95 \%$ for both $\mathrm{UV} / \mathrm{TiO}_{2}$ and $\mathrm{UV} / \mathrm{H}_{2} \mathrm{O}_{2}$ processes. Concentration of ferrous salt $(60$ $\mathrm{ppm}$ ) was considered as an optimal value to carry out the $\mathrm{UV} / \mathrm{H}_{2} \mathrm{O}_{2} / \mathrm{Fe}^{2+}$ process for MGO decolorization. Influence of oxidant $\left(\mathrm{H}_{2} \mathrm{O}_{2}\right)$ and $\mathrm{Fe}^{2+}$ ions for oxidation of $\mathrm{MGO}$ was studied in Photo-Fenton process. Sulphate radical based AOPs was proved to be more effective in treating MGO dye with irradiation. Results indicate that decolorization efficiency by Photochemical AOPs for MGO dye in photochemical reactor were more efficient. Pseudo-firstorder model of kinetics was noticed to be the best model fit to explain the decolorization of MGO dye solution.

Keywords: Wastewater treatment, advanced oxidation processes (AOPs); Fenton process; UV irradiation; textile effluent; hydroxyl and sulphate radicals; kinetics and photocatalysis.

\section{Introduction}

Environmental pollution and its related problems are becoming increasingly serious (Xiao et al., 2018). It might be due to the speedy expansion of world population and the increasing urbanization and automation or industrialization (He et al., 2018). Discharge of water pollutants from industries into fresh water bodies has been projected as a main reason of environmental pollution (Maiti et al., 2017). Among different types of dye discharged from industries, organic dyes are mostly used chemicals which mainly released from textile industries, paper and pulp, leather and food industries (Vikranta et al., 2018). It is testified that more than $7 \times 10^{7}$ tons of dyestuffs are manufactured annually. Out of which, 60-70\% counts only for class of azo dyes (Sarkheil et al., 2014). About 10 to $15 \%$ of dyes are discharged into environment in dyeing processes (Ratna, 2012). Thus, textile industries have become a source of environmental pollution (Rajoriya et al., 2018). Now, it's a serious challenge to the researchers working in the environmental field, due to the health risks and the presence of the undesirable distinct colours of organic dyes. Recently, many processes including adsorption (Guan et al., 2018; Abbasi and Asgari, 2018), biodegradation (Shanmugam et al., 2017; Martorell et al., 2017), coagulation (Li et al., 2016; Ahmed et al., 2018) have been started to apply for dye removal. But these processes are having certain limitations. Biological processes take too much time for removal of dyes. Rest of processes is having lack of process efficiency. Henceforth, it is necessary to find out any alternative process. AOPs are more useful processes for removal of water contaminants (Dewil et al., 2017; Samarghandi et al., 2018; Fraiese et al., 2019) and used highly reactive and short lived hydroxyl $\left({ }^{\circ} \mathrm{OH}\right)$ radicals for decolorization of organic dyes (Luo et al., 2018). AOPs include both homogeneous and heterogenous type. Homogeneous AOPs consists of Fenton's process without irradiation, UV-photolysis and Photo-Fenton with irradiation. Moreover, heterogeneous AOPs were applied using some solid catalyst like titanium dioxide $\left(\mathrm{TiO}_{2}\right)$ and their modified forms and processes include $\mathrm{UV} / \mathrm{TiO}_{2}$ and $\mathrm{UV} / \mathrm{TiO}_{2} / \mathrm{H}_{2} \mathrm{O}_{2}$ processes. Guimaraes et al. (2012) reported comparative study for oxidation of aqueous Reactive blue 19 (RB 19) dye via photochemical AOPs. Efficiency of photolysis, peroxidation, peroxidation with irradiation, Fenton oxidation and Fenton-like process for decolorization of RB 19 were tested. UV/ $\mathrm{H}_{2} \mathrm{O}_{2} / \mathrm{Fe}^{2+}$ process was efficient for RB 19 dye decoloration (Guimaraes et al., 2012). Bousnoubra et al. (2017) studied removal of Bromo cresol purple dye by various photochemical AOPs in aqueous medium and process efficiency was more in photo-Fenton (Bousnoubra et al., 2017). The ${ }^{\bullet} \mathrm{OH}$ radicals limit their efficiency in challenging environmental conditions. In order to overcome such limitation of ${ }^{\bullet} \mathrm{OH}$ 
radical based AOPs (HR-AOPs), new methodology was adopted, called as sulphate radical based AOPs (SR-AOPs). It has been used for removal of contaminants in wastewater and extensively investigated (Brienza et al., 2017). In this study, Malachite Green Oxalate (MGO) dye was chosen as a target water pollutant. MGO dye is mostly used in textile, paper, plastics and pharmaceuticals. It causes some damaging effect to ecology and its contact by human skin leashes to irritation, pain and redness. Henceforth, removal of MGO dye from textile wastewaters become ecologically vital (Elhami et al., 2015). Additionally, this report was focused on finding decolorization efficiency of MGO dye using different types of homogeneous and heterogenous types of AOPs. The effects of ferrous ion $\left(\mathrm{Fe}^{2+}\right)$ and oxidant concentration was reported on \% decolorization of MGO dye in photo-Fenton process. Results obtained in HR-AOPs was compared with SR-AOPs. Kinetic studies for both processes i.e., HR-AOPs and SR-AOPs done and compared. When Fenton's process (reaction 01) is carried out with irradiation (photo-Fenton process), Ferrous ions $\left(\mathrm{Fe}^{2+}\right)$ could be generated as per reaction (reaction 2 ):

$$
\mathrm{Fe}^{2+}+\mathrm{H}_{2} \mathrm{O}_{2} \rightarrow \mathrm{Fe}^{3+}+\mathrm{HO}^{\bullet}+\mathrm{HO}^{-}
$$

$$
\mathrm{Fe}^{3+}+\mathrm{H}_{2} \mathrm{O} \stackrel{h v}{\longrightarrow} \mathrm{Fe}^{2+}+\mathrm{H}^{+}+\mathrm{HO}^{\mathrm{g}} \quad \lambda<580 \mathrm{~nm}
$$

In case of the $\mathrm{TiO}_{2}$ photocatalysis, pair of holes (positively charged) and electrons are formed in valence and conduction band (reaction 3 ).

$$
\mathrm{TiO}_{2}+h v \rightarrow h^{+}+e^{-}+\mathrm{HO}^{-} \quad \lambda<400 \mathrm{~nm}
$$

Then the hydroxyl radicals are formed through the reactions (reaction 4 and 5):

$$
h^{+}+\mathrm{H}_{2} \mathrm{O} \rightarrow \mathrm{H}^{+}+\mathrm{HO}^{\bullet}
$$

$$
h^{+}+\mathrm{HO}^{-} \rightarrow \mathrm{HO}^{\bullet}
$$

$\mathrm{TiO}_{2}$ was used to carry out oxidation of $\mathrm{MGO}$ dye in heterogenous type of AOPs $\left(\mathrm{UV} / \mathrm{TiO}_{2}\right.$ and $\left.\mathrm{UV} / \mathrm{TiO}_{2} / \mathrm{H}_{2} \mathrm{O}_{2}\right)$. Process efficiency of heterogenous and homogenous AOPs were demonstrated for removal of MGO dye in aqueous medium. Both catalysts $\left(\mathrm{Fe}^{2+}\right.$ salt and $\left.\mathrm{TiO}_{2}\right)$ play significant role in homogeneous and heterogeneous type of AOPs. In short, this study covers comparative assessment of Photochemical AOPs for MGO dye removal in wastewater. Table 1 shows physicochemical properties of MGO dye (Raval et al., 2016).

\section{Materials and methods}

\subsection{Materials}

Malachite Green Oxalate, MGO (Fast Green for Microscopy) dye was procured from LOBA chemie. Analytical grade $\mathrm{H}_{2} \mathrm{SO}_{4}, 98 \%$ and $\mathrm{NaOH}, 97 \%$ and $30 \% \mathrm{H}_{2} \mathrm{O}_{2}$ $(\mathrm{w} / \mathrm{v})$ was supplied by Merck. Titanium dioxide $\left(\mathrm{TiO}_{2}\right)$ of anatase phase was used as photocatalyst.
Sodium per-sulphate $\left(\mathrm{Na}_{2} \mathrm{~S}_{2} \mathrm{O}_{8}\right)$ was used for generation of sulphate radicals. All the required reagents were used without further purification in decolorization experiments.

\begin{tabular}{|c|c|c|}
\hline Properties & \multicolumn{2}{|c|}{ Molecular structure of MGO dye } \\
\hline $\mathrm{MW}$ (g/mol) - & \multirow{8}{*}{ (c) } & \multirow{7}{*}{$(\mathrm{COOH})_{2}$} \\
\hline $972.02 \mathrm{~g} / \mathrm{mol}$ & & \\
\hline Formula - & & \\
\hline $\mathrm{C}_{52} \mathrm{H}_{54} \mathrm{~N}_{4} \mathrm{O}_{12}$ & & \\
\hline Max. wavelength - & & \\
\hline $618 \mathrm{~nm}$ & & \\
\hline Color Index (C. I.) & & \\
\hline No. 42000 & & \\
\hline
\end{tabular}
Table 2 shows the experimental parameters tested, the indices and the result values of experiments done for the decolorization of MGO dye in aqueous medium.

Table 1. Characteristics of MGO dye

\subsection{Instruments used with some analytical procedures}

$\mathrm{pH}$ value of an aqueous MGO dye was evaluated using model- $\mathrm{PH}-200 \mathrm{pH}$ meter. Unknown concentration of aqueous dye at various time interval was achieved with measurement of value of absorbance at $\lambda \max , 618 \mathrm{~nm}$; percentage decolorization efficiency using equation (Eq. 1) was determined with calibration curve which was plotted from known concentration of dye solutions with their respective absorbance values. Shimadzu 1800 UV-Vis spectrophotometer was used for measurement of absorbance via quartz cell (path length of $1 \mathrm{~cm}$ ). Equation for calibration curve of an aqueous MGO dye was $Y_{M G O}=0.1361 X_{M G O}-0.0328 ; R^{2}=0.988$; where $Y_{M G O}$ is the value of absorbance at $618 \mathrm{~nm}$ and $X_{M G O}$ is MGO dye concentration in ppm. MGO dye percentage decolorization was calculated with equation (01).

$$
\text { Percentage decolorization (in \%) }=\left\{\frac{\mathrm{c}_{0}-\mathrm{c}_{\mathrm{t}}}{\mathrm{c}_{0}}\right\} \times 100
$$

Where, $C_{0}$ : Initial concentration of MGO dye and $C_{t}$ being MGO dye concentration at time $t$. Centrifuge (Model: Remi R-4C) was used to separate dispersed $\mathrm{TiO}_{2}$ from samples.

\subsection{Photo-chemical reactor set up}

It was used to study photo-catalytic reactions with UV irradiation for decolorization of MGO dye. Experimental runs were performed in cylindrical photochemical reactor with an effectual reactor volume, $1.47 \mathrm{~L}$ and feed tank volume $5 \mathrm{~L}$. This apparatus was used to study mineralization of liquid effluent industrial streams water. Setup consists of reactor with inside reflecting surface and UV irradiation surrounding glass/quartz tube placed centrally in reactor. Figure 1 shows complete set up for photochemical reactor. The technical details of used photo-chemical reactor are: Feed tank material- SS304; Feed circulation- Magnetic pump composed of PP (polypropylene). Maximum working temperature $-80^{\circ} \mathrm{C}$; Flow Measurement-Rotameter and UV tubes-4, intensity of $8 \mathrm{~W}$ each (low pressure mercury vapor lamp). 
Table 2. Parameters tested, the indices and result values of the experiments

\begin{tabular}{|c|c|c|c|c|c|}
\hline $\begin{array}{l}\text { Serial } \\
\text { No. }\end{array}$ & Parameter tested & \multicolumn{2}{|c|}{ Operating conditions } & $\begin{array}{l}\text { Values/process } \\
\text { taken for study }\end{array}$ & $\begin{array}{c}\text { Decolorization } \\
\text { obtained (\%) }\end{array}$ \\
\hline \multirow{4}{*}{1} & \multirow{4}{*}{$\begin{array}{l}\text { Effect of dye } \\
\text { concentration in } \\
\text { photolysis }\end{array}$} & \multirow{4}{*}{\multicolumn{2}{|c|}{$\begin{array}{l}4 \mathrm{~L} \text { of } \mathrm{MGOdye} \text { solution, Flow rate: } 10 \mathrm{LPH} \\
\text { and } \mathrm{pH}=3.0 \text { and } 90 \mathrm{~min} \text { of reaction time }\end{array}$}} & 50 ppm & 75.00 \\
\hline & & & & 100 ppm & 81.00 \\
\hline & & & & 150 ppm & 70.00 \\
\hline & & & & $200 \mathrm{ppm}$ & 61.00 \\
\hline \multirow{5}{*}{2} & \multirow{5}{*}{$\begin{array}{l}\text { Comparison of photo- } \\
\text { chemical AOPs }\end{array}$} & \multirow{5}{*}{\multicolumn{2}{|c|}{$\begin{array}{l}\text { Flow rate of } 10 \mathrm{LPH} ; 12 \\
\mathrm{mM} \text { of } \mathrm{H}_{2} \mathrm{O}_{2}, \mathrm{Fe}^{2+} 60 \\
\text { ppm, } \mathrm{TiO}_{2} 0.6 \mathrm{gm} / \mathrm{L} \\
\text { irradiation of } 32 \mathrm{~W}\end{array}$}} & UV alone & 77.00 \\
\hline & & & & $\mathrm{UV} / \mathrm{TiO}_{2}$ & 95.00 \\
\hline & & & & $\mathrm{UV} / \mathrm{H}_{2} \mathrm{O}_{2}$ & 95.00 \\
\hline & & & & $\mathrm{UV} / \mathrm{H}_{2} \mathrm{O}_{2} / \mathrm{TiO}_{2}$ & 97.00 \\
\hline & & & & $\mathrm{UV} / \mathrm{H}_{2} \mathrm{O}_{2} / \mathrm{Fe}^{2+}$ & 98.00 \\
\hline \multirow{4}{*}{3} & \multirow{4}{*}{$\begin{array}{l}\text { Effect of } \mathrm{Fe}^{2+} \text { ion in } \\
\text { Photo-Fenton process }\end{array}$} & \multirow{4}{*}{$\begin{array}{c}\text { Flow rate of } 10 \mathrm{LPH} ; 12 \\
\mathrm{mM} \text { of } \mathrm{H}_{2} \mathrm{O}_{2} \text {, irradiation } \\
\text { of } 32 \mathrm{~W}\end{array}$} & \multirow{7}{*}{$\begin{array}{l}4 \text { Litres of } 100 \\
\text { ppm [MGO]dye } \\
\text { solution; pH } 3.0 \\
\text { for } 60 \mathrm{~min}\end{array}$} & 20 ppm & 78.00 \\
\hline & & & & 40 ppm & 88.00 \\
\hline & & & & 60 ppm & 98.00 \\
\hline & & & & 80 ppm & 85.00 \\
\hline \multirow[b]{3}{*}{4} & \multirow{3}{*}{$\begin{array}{c}\text { Effect of } \mathrm{H}_{2} \mathrm{O}_{2} \\
\text { concentration in Photo- } \\
\text { Fenton, } \mathrm{TiO}_{2} \text { photolysis } \\
\text { and UV-assisted } \\
\text { processes }\end{array}$} & \multirow{3}{*}{$\begin{array}{l}\text { Flow rate of } 10 \mathrm{LPH} ; 12 \\
\mathrm{mM} \text { of } \mathrm{H}_{2} \mathrm{O}_{2}, \mathrm{Fe}^{2+} 60 \\
\mathrm{ppm}, \mathrm{TiO}_{2} 0.6 \mathrm{gm} / \mathrm{L} \\
\text { irradiation of } 32 \mathrm{~W}\end{array}$} & & $\mathrm{UV} / \mathrm{H}_{2} \mathrm{O}_{2}$ & 95.00 \\
\hline & & & & $\mathrm{UV} / \mathrm{H}_{2} \mathrm{O}_{2} / \mathrm{TiO}_{2}$ & 97.00 \\
\hline & & & & $\mathrm{UV} / \mathrm{H}_{2} \mathrm{O}_{2} / \mathrm{Fe}^{2+}$ & 98.00 \\
\hline \multirow{2}{*}{5} & \multirow{2}{*}{$\begin{array}{l}\text { Effect of UV light intensity } \\
\text { in UV photolysis }\end{array}$} & \multirow{2}{*}{ Flow rate: $10 \mathrm{LPH}$} & & $24 \mathrm{~W}$ & 66.00 \\
\hline & & & & $32 \mathrm{~W}$ & 77.00 \\
\hline \multirow{3}{*}{6} & \multirow{3}{*}{$\begin{array}{l}\text { Effect of varying flowrate } \\
\text { in UV photolysis }\end{array}$} & \multirow{3}{*}{ Light intensity: $32 \mathrm{~W}$} & & $5 \mathrm{LPH}$ & 60.00 \\
\hline & & & & $10 \mathrm{LPH}$ & 77.00 \\
\hline & & & & $20 \mathrm{LPH}$ & 66.00 \\
\hline \multirow{3}{*}{7} & \multirow{3}{*}{$\begin{array}{l}\text { Effect of sulphate radical } \\
\text { concentrations with UV- } \\
\text { Irradiation }\end{array}$} & \multirow{3}{*}{$\begin{array}{l}\text { Flow rate of } 10 \mathrm{LPH} \text {, } \\
\text { Light intensity } 32 \mathrm{~W}\end{array}$} & & $0.84 \mathrm{mM}$ & 95.20 \\
\hline & & & & $1.68 \mathrm{mM}$ & 96.71 \\
\hline & & & & $3.36 \mathrm{mM}$ & 95.45 \\
\hline
\end{tabular}

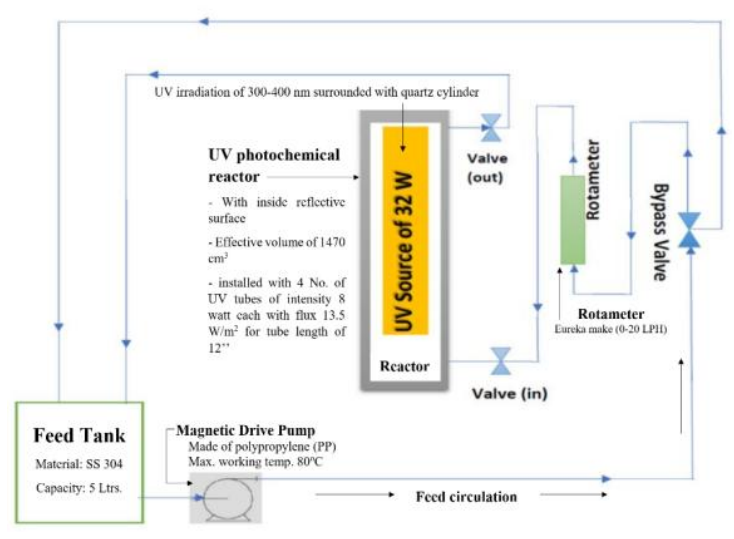

Figure 1. Schematic representation of UV photo-chemical reactor for the decolorization studies of MGO dye

\subsection{AOP experiments}

\subsubsection{Direct photolysis}

100 ppm of MGO dye solution was prepared and irradiated for $60 \mathrm{~min}$ with minimum sampling interval. Samples were immediately analysed for percentage decolorization.

\subsubsection{Photo-degradation using other photochemical processes}

Fenton-like degradation of model dye solution: For photochemical treatment of MGO dye, solution of desired concentration was prepared synthetically. Its $\mathrm{pH}$ was adjusted to 3 (acidic) with the help of $1 \mathrm{M}$ solutions of $\mathrm{H}_{2} \mathrm{SO}_{4}$ and $\mathrm{NaOH}$. Required amount of photo-catalyst was added for better process efficiency. In order to generate a greater number of hydroxyl radicals, calculated amount of $\mathrm{H}_{2} \mathrm{O}_{2}$ was added. Whole mixture was poured into feed tank of reactor. Switch on unit, flow rate was adjusted to determined value, samples were collected after specific interval of time. Unknown concentration of MGO dye in aliquots was measured by finding absorption intensity at $618 \mathrm{~nm}$ of maximum wavelength with calibration curve of MGO dye.

\section{Results and discussion}

Trends in decolorization efficiency of MGO dye using various AOPs is presented by showing the effect of various experimental parameters.

3.1. Effect of dye concentration on its \% decolorization in photolysis

UV-photolysis is a popular way for producing free radicals via cleavage of sigma-bond (Moreira et al., 2017; Vaid et al., 2018). Generated radicals exist normally as precursors which produce more free radicals. Several steps are involved in photochemical reaction of a dye. Initially, molecule is excited through absorption of one photon. Excited molecule further carries out chemical reaction resulting in oxidation of organic matter in an aqueous media (Shankaraiah et al., 2017). Dye of varying concentrations in range of 50-200 ppm was used to obtain 
trend in \% decolorization. Figure 2 reports \% decolorization with respect to reaction time while varying initial concentration of dye. Dye was efficiently decolorized to $81 \%$ for $100 \mathrm{ppm}$ in $90 \mathrm{~min}$. At higher concentrations in range of $150-200$ ppm, \% decolorization decreased to $60-70 \%$. Percentage decolorization was found to be maximum at 100 ppm concentration of aqueous MGO. Then $100 \mathrm{ppm}$ concentration of dye was used throughout the experiments. Moreira et al. (2017) studied the degradation of atrazine in aqueous solution with UV treatment alone to exposure of $1200 \mathrm{~s}$ and concluded that the system after $1200 \mathrm{~s}$ of exposure to UV irradiation didn't reach the complete degradation of water contaminant (Moreira et al., 2017). Similar condition was also happened with the MGO dye solution. Only $81 \%$ of degradation was observed for a initial dye concentration of $100 \mathrm{ppm}$ within 90 min of UV exposure. Shankaraiah et al. (2017) also proved that the UV treatment alone could not oxidise the targeted antibiotic gemifloxacin completely in wastewater (Shankaraiah et al., 2017).

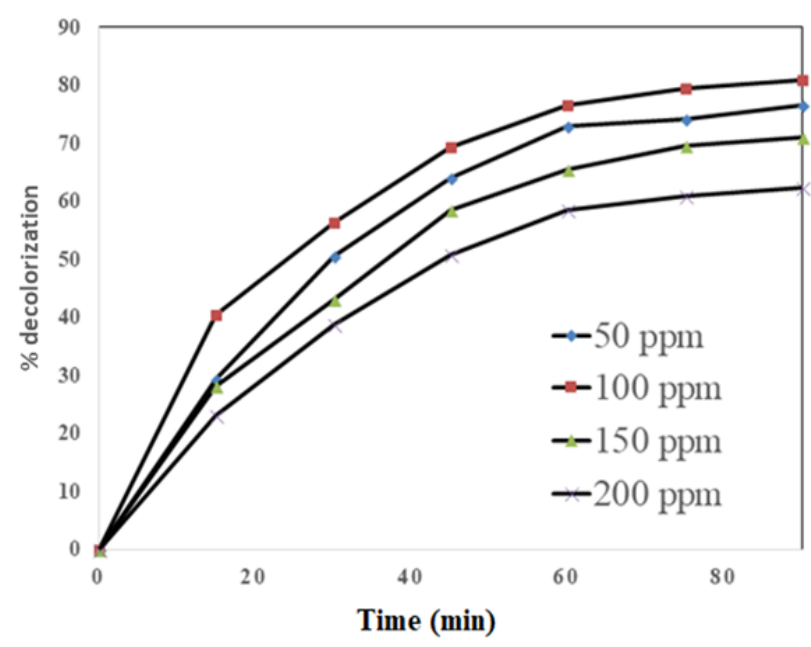

Figure 2. UV-photolysis of MGO dye in aqueous media at varying concentration of dye (Reaction conditions: $4 \mathrm{~L}$ of dye solution,

Flow rate $10 \mathrm{LPH}$ and $\mathrm{pH}=3.0$ )

\subsection{Comparison of various photo-chemical advanced oxidation processes against decolorization}

In photo-Fenton process, $\mathrm{Fe}^{2+}$ ions and $\mathrm{H}_{2} \mathrm{O}_{2}$ was used in combination with irradiation. This process is called as Photo-Fenton as process uses Fenton's reagent with UV (Aljuboury and Palaniandy, 2017). In UV/ $\mathrm{H}_{2} \mathrm{O}_{2} / \mathrm{TiO}_{2}$ (photo-catalysis), higher rate of decolorization was found due to the use of catalyst $\left(\mathrm{TiO}_{2}\right)$ with $\mathrm{H}_{2} \mathrm{O}_{2}$. Initially, rate of decolorization was high due to generation of highly reactive ${ }^{\circ} \mathrm{OH}$ radicals. Percentage decolorization was around $98 \%$ and $97 \%$ for Photo-Fenton and $\mathrm{TiO}_{2}-$ photocatalysis processes in $60 \mathrm{~min}$. MGO dye was decolorized using various photochemical AOPs in order to find an efficiency of different treatment systems. UV photolysis alone and use of $\mathrm{UV} / \mathrm{H}_{2} \mathrm{O}_{2}$ processes could not totally decolorize dye (Al Momani et al., 2004). UV/TiO and $\mathrm{UV} / \mathrm{H}_{2} \mathrm{O}_{2}$ photochemical AOPs almost achieved $95 \%$ decolorization for oxidation of MGO. Percentage decolorization was found less in UV photolysis $(77 \%$ in 60 min again). Thus, the use of UV with $\mathrm{TiO}_{2}$ and $\mathrm{Fe}^{2+}$ in presence of $\mathrm{H}_{2} \mathrm{O}_{2}$ showed considerable removal for MGO dye (Lutterbeck et al., 2015; Ortega-Liebana et al., 2012). Figure 3 indicates comparative study of various photochemical AOPs for decolorization of MGO dye solution. Decoloration for $\mathrm{MGO}$ dye was found to decrease in order of: Photo-Fenton $>\mathrm{UV} / \mathrm{H}_{2} \mathrm{O}_{2} / \mathrm{TiO}_{2}>\mathrm{UV} /$ $\mathrm{TiO}_{2}>\mathrm{UV} / \mathrm{H}_{2} \mathrm{O}_{2}>\mathrm{UV}$-photolysis.

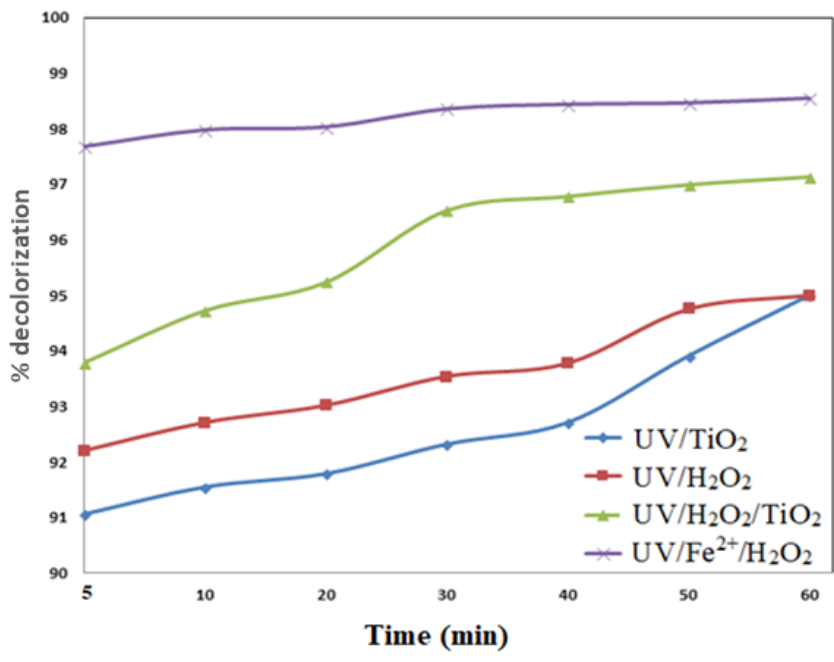

Figure 3. Comparison of various photo-chemical AOPs against decolorization (Reaction Conditions:[MGO] 100 ppm, $12 \mathrm{mM}$ of $\mathrm{H}_{2} \mathrm{O}_{2}, \mathrm{pH} 3.0, \mathrm{Fe}^{2+} 60 \mathrm{ppm}, \mathrm{TiO}_{2} 0.6 \mathrm{gm} / \mathrm{L}$, irradiation of $32 \mathrm{~W}$ for $60 \mathrm{~min}$ of reaction time)

Experimental parameters are given in figure caption (Figure 3). From published literature data, it was observed that photochemical AOPs for remediation of aqueous water pollutant including organic dyes occurs at $\mathrm{pH}-3$ (acidic) (Jamil et al., 2011; Villegas-Guzman et al., 2017). Solutions at $\mathrm{pH} 3$ were prepared by drop wise addition of $0.1 \mathrm{~N} \mathrm{NaOH}$ to dye solution until the desired $\mathrm{pH}$ was obtained. Comparative study of different photochemical AOPs shows that photo-Fenton process was best and efficient for removal of MGO dye in acidic environments.

\subsection{Effect of $\mathrm{Fe}^{2+}$ ion concentration in photo-Fenton process}

Experimental runs were performed by varying ferrous ions concentration in range of $20-80 \mathrm{ppm}$. It was observed that degradation rate was increased as iron concentration increased $(20-60 \mathrm{ppm})$. Further increase in $\mathrm{Fe}^{2+}$ ions to $80 \mathrm{ppm}$ led to a reduction in degradation rate of MGO dye in aqueous medium. As concentration increases, production of ${ }^{\bullet} \mathrm{OH}$ radicals also increase. Most of these radicals are utilized in side reactions even earlier they can be used. In photo-Fenton process, supplement of more amount of ferrous salt caused in brown turbidity of Fe (III) hydroxide which cause recombination of ${ }^{\circ} \mathrm{OH}$ radicals (reaction 6) (Jamil et al., 2011). This might have happened while using $80 \mathrm{ppm}$ ferrous ion concentration in 
experimental run. Additionally, the possible generation of intermediates (Iron IV species) like ferryl iron $(\mathrm{FeO})^{2+}$ can be the cause for reduction in decolorization rate of dye. Jamil et al. (2011) observed the reduction in Chemical Oxygen Demand (COD) while treating the biodegradibility of paper mill wastewater with the use of excess amount of ferrous ions. The possible generation of iron IV species (intermediate) was the main cause for decrement in COD values. This means that COD value was influenced with the utilization of extra quantity of $\mathrm{Fe}^{2+}$ salt in solution (Jamil et al., 2011). Figure 4 reports the effect of ferrous ion concentration on dye degradation in Photo-Fenton process.

$$
\mathrm{Fe}^{2+}+\mathrm{HO}^{\bullet} \rightarrow \mathrm{Fe}^{3+}+\mathrm{HO}^{-}
$$

Possible side reactions which interfere the generation of hydroxyl radicals are harmful for decolorization of dye (reactions 7-9).

$$
\begin{aligned}
& \mathrm{H}_{2} \mathrm{O}_{2}+\mathrm{Fe}^{2+} \rightarrow(\mathrm{FeO})^{2+}+\mathrm{H}_{2} \mathrm{O} \\
& (\mathrm{FeO})^{2+}+\mathrm{Fe}^{2+}+\mathrm{H}^{+} \rightarrow(\mathrm{FeOH})^{2+}+\mathrm{Fe}^{3+} \\
& (\mathrm{FeOH})^{2+}+\mathrm{H}^{+} \rightarrow \mathrm{Fe}^{3+}+\mathrm{H}_{2} \mathrm{O}
\end{aligned}
$$

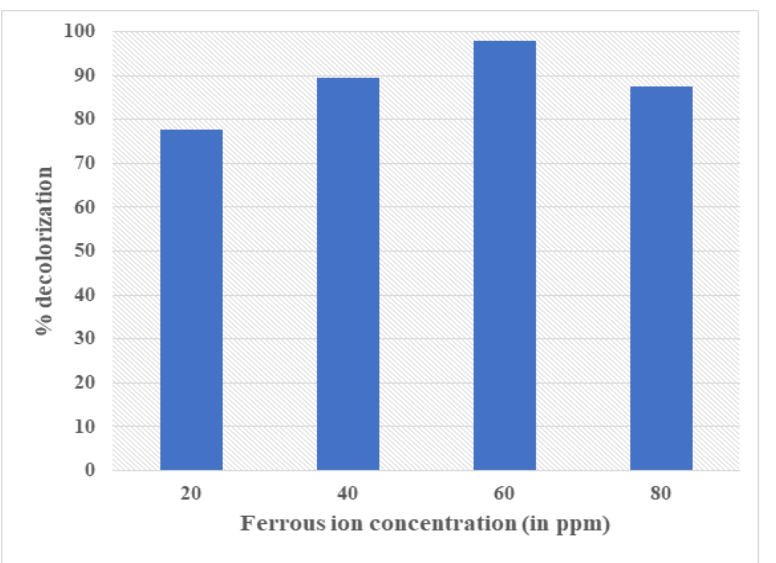

Figure 4. Effect of ferrous ion concentration on dye degradation in Photo-Fenton process (Reaction Conditions:[MGO $]_{0} 100$ ppm,

$12 \mathrm{mM}$ of $\mathrm{H}_{2} \mathrm{O}_{2}, \mathrm{pH} 3.0$, irradiation of $32 \mathrm{~W}$ for $60 \mathrm{~min}$ of reaction time)

\subsection{Effect of oxidant concentration on dye decolorization in photo-Fenton, $\mathrm{TiO}_{2}$ photolysis and UV-assisted $\mathrm{H}_{2} \mathrm{O}_{2}$ processes}

Hydrogen peroxide doses in photochemical AOPs (photoFenton, $\mathrm{TiO}_{2}$ photolysis and UV-assisted $\mathrm{H}_{2} \mathrm{O}_{2}$ ) processes were varied from 6 to $36 \mathrm{mM}$. 88.61\% decolorization was noticed for a dose of $6 \mathrm{mM} \mathrm{H}_{2} \mathrm{O}_{2}$ in photo-Fenton process keeping rest of experimental conditions same. It indicates the hydroxyl radical formation in reaction mixture. Initially, oxidation reactions for decolorization of dye was faster. As time passes, the rate of decolorization becomes slow (Lutterbeck et al., 2015). Figure 5 shows the influence of oxidant concentration on dye decolorization in Photo-Fenton, $\mathrm{TiO}_{2}$ photolysis and UV-assisted $\mathrm{H}_{2} \mathrm{O}_{2}$ processes. Beyond $12 \mathrm{mM}$ dose of $\mathrm{H}_{2} \mathrm{O}_{2}$ in reaction media, decrement in value of $\%$ decolorization was found. It might have happened due to scavenging effects of excessive $\mathrm{H}_{2} \mathrm{O}_{2}$ or recombination of ${ }^{\circ} \mathrm{OH}$ radicals (Rahim Pouran et al., 2015. Higher concentrations of $\mathrm{H}_{2} \mathrm{O}_{2}$ decrease the processes efficiency generally through (a)auto decomposition of $\mathrm{H}_{2} \mathrm{O}_{2}$ to water and oxygen (reaction 10), (b) scavenging effects of hydroxyl radical with oxidant that produces per-hydroxyl radical $\left(\mathrm{HO}_{2}{ }^{\circ}\right)$ ions (reaction 11 ) and subsequent reaction with ${ }^{\circ} \mathrm{OH}$ radicals destabilize the reaction rate (reaction 12 ).

$$
2 \mathrm{H}_{2} \mathrm{O}_{2} \rightarrow 2 \mathrm{H}_{2} \mathrm{O}_{2}+\mathrm{O}_{2}
$$

$$
\mathrm{H}_{2} \mathrm{O}_{2}+\mathrm{HO}^{\bullet} \rightarrow \mathrm{HO}_{2}^{\bullet}+\mathrm{H}_{2} \mathrm{O}
$$

$$
\mathrm{HO}_{2}{ }^{\circ}+\mathrm{HO}^{\bullet} \rightarrow \mathrm{H}_{2} \mathrm{O}+\mathrm{O}_{2}
$$

Lutterbeck et al. (2015) reported the photodegradation (UV/ $\mathrm{H}_{2} \mathrm{O}_{2}$ and with Photo-Fenton) for the degradation of anticancer drug and alkylating agent cyclophosphamide (CP). $\mathrm{H}_{2} \mathrm{O}_{2}$ concentration was varied in range of $9.8 \mathrm{mM}$ to $19.6 \mathrm{mM}$ in $\mathrm{UV} / \mathrm{H}_{2} \mathrm{O}_{2}$ process. $72.5 \%$ of mineralization (for $20 \mathrm{ppm}$ of (P) was obtained in $256 \mathrm{~min}$ for the oxidant dose of $9.8 \mathrm{mM}$. But above this concentration of oxidant, mineralization efficiency was found to be decreased to $65.2 \%$ and $52.8 \%$ with oxidant doses of $14.7 \mathrm{mM}$ and $19.6 \mathrm{mM}$ respectively. The decrease in mineralization was due to the inhibitory effect caused by extra amount of $\mathrm{H}_{2} \mathrm{O}_{2}$. Excess amount of oxidant acts as a hole scavenger that forms perhydroxyl radicals which is much less reactive than hydroxyl radicals. Therefore, it is always undesirable to use the amount of oxidant more than the optimum (Lutterbeck et al., 2015).

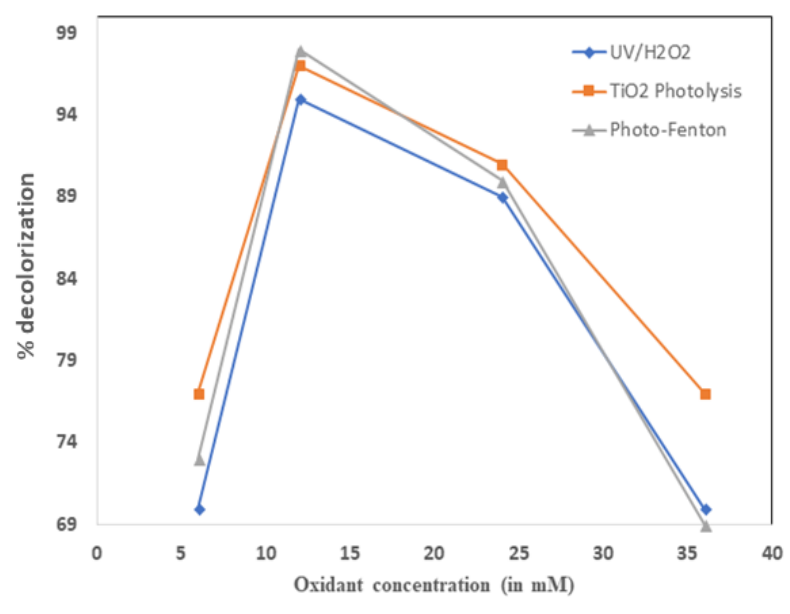

Figure 5. Effect of oxidant concentration on dye decolorization in Photo-Fenton, $\mathrm{TiO}_{2}$ photolysis and UV-assisted $\mathrm{H}_{2} \mathrm{O}_{2}$ processes (Reaction Conditions: [MGO] 100 ppm, pH 3.0, Fe ${ }^{2+} 60$ ppm, $\mathrm{TiO}_{2}$ $0.6 \mathrm{gm} / \mathrm{L}$, irradiation of $32 \mathrm{~W}$ for $60 \mathrm{~min}$ of reaction time) 


\subsection{Effect of UV light intensity}

Decolorization rate for oxidation of dye increases with increasing light intensity as more light energy is available (Garcia et al., 2017). Experiments were performed to understand the increasing trend by using simple UV treatment without any catalyst. From our experiments, it was found that the reaction was fastest at $32 \mathrm{~W}$ UV intensity. It was allowed to undergo decolorization for 60 min under UV light of intensities $24 \mathrm{~W}$ and $32 \mathrm{~W}$ (mercury lamps) respectively. Figure 6 indicates the effect of UV light intensity on percentage decolorization of MGO dye. The results show that more MGO dye molecules were excited and decolorized as the light intensity of UV irradiation was increased from $24 \mathrm{~W}$ to $32 \mathrm{~W}$.

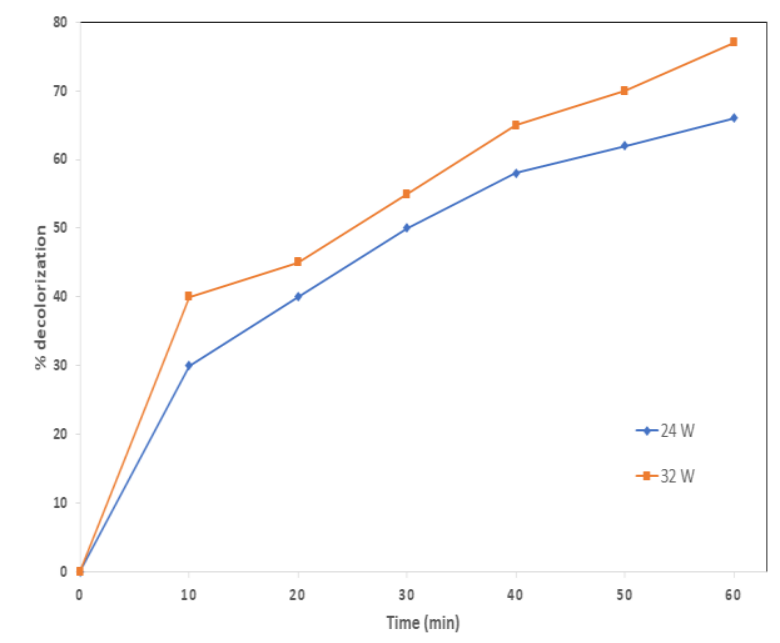

Figure 6. Effect of UV light intensity on percentage decolorization of MGO dye in UV-photolysis process (Reaction conditions: $4 \mathrm{~L}$ of dye solution of $100 \mathrm{ppm}$ concentration, Flow rate $10 \mathrm{LPH}$ and $\mathrm{pH}=3.0$ )

The results observed for photodegradation of MGO dye in our study is similar to the results obtained in photooxidation studies of the 2,2, 4,4, 5,5- Hexachlorobiphenyl or PCB 153 (Macawile et al., 2011). Around 77\% and 66\% decolorization was obtained for MGO dye solution while using light intensities of UV lamps of $32 \mathrm{~W}$ and $24 \mathrm{~W}$, respectively. Macawile et al. (2011) investigated the photodegradation of polychlorinated biphenyls (PCB-153) using ultraviolet irradiation with $\mathrm{H}_{2} \mathrm{O}_{2} .17 \mathrm{~W}$ and $24 \mathrm{~W}$ of UV sources was used for 80 ppb concentration of PCB-153 contaminant in water. $77.84 \%$ of degrdation was reported for $30 \mathrm{~min}$ of exposure to $17 \mathrm{~W}$ of UV irradiation. When PCB-153 was irradiated with a $24 \mathrm{~W}$ of irradiation (attributed to higher amount of energy, $470 \mathrm{~kJ} / \mathrm{mol}$ ), fastly caused the cleavage of organic compound bonds. This leads to the faster reduction in concentration of PCB153 and generation of more radicals intermediates. Free radicals that are produced from cleavage are highly reactive, caused the drastic change in PCB-153 concentration in initial stages. The final results concluded that more number of excited PCB molecules were generated and destryed as the value of UV light intensity increased from $17 \mathrm{~W}$ to $24 \mathrm{~W}$ (Macawile et al., 2011).

\subsection{Effect of varying flow rate}

In order to find out optimum flowrate value, 4.0 L dye containing $100 \mathrm{ppm}$ concentration of MGO dye was treated in photochemical reactor at different flowrates (5, 10 and $20 \mathrm{LPH}$, respectively). Figure 7 shows influence of varying flow rate in continuous type of photochemical reactor on MGO dye decolorization. When flow rate was high in MGO decolorization (at $20 \mathrm{LPH}$ ), the residence time of a particular elemental segment of dye would be less. Hence, decolorization of MGO dye won't be effective. But, when it was kept to $5 \mathrm{LPH}$ in process (lower value of flowrate), the time taken for decolorization by overall process will be high. Hence, flow rate should be maintained in such a way that there will be optimum decolorization without time consuming. In MGO dye decolorization, $10 \mathrm{LPH}$ of flowrate was noticed as an optimum value. $77 \%$ decolorization was obtained for $10 \mathrm{LPH}$ flowrate in $60 \mathrm{~min}$. But it was reduced to $65 \%$ for $20 \mathrm{LPH}$. When flowrate was adjusted to $5 \mathrm{LPH}, \%$ decolorization was just reached to $60 \%$ in $60 \mathrm{~min}$. Water photolysis happens in a $0.3 \mathrm{~cm}$ layer close to UV lamp, where UV photons are absorbed. Besides, considering the diffusion coefficient of $\mathrm{HO}^{\bullet}$ radicals $\left(2.3 \times 10^{-5} \mathrm{~cm}^{2} \mathrm{~s}^{-1}\right)$ and its average life time in water $\left(10^{-9}-10^{-6} \mathrm{~s}\right)$, hydroxyl radicals are expected to react in the location where they get generated. Thus, decolorization of dye happens in UV illuminated area of photochemical reactor. This makes mass transfer and diffusion resistance difficult since reagents (aqueous dye and $\mathrm{O}_{2}$ ) should diffuse from bulk towards the volume illuminated by UV irradiation (Imoberdorf and Mohseni, 2012). Diffusive resistances can be decreased by increasing the internal mixing with higher flowrate values.

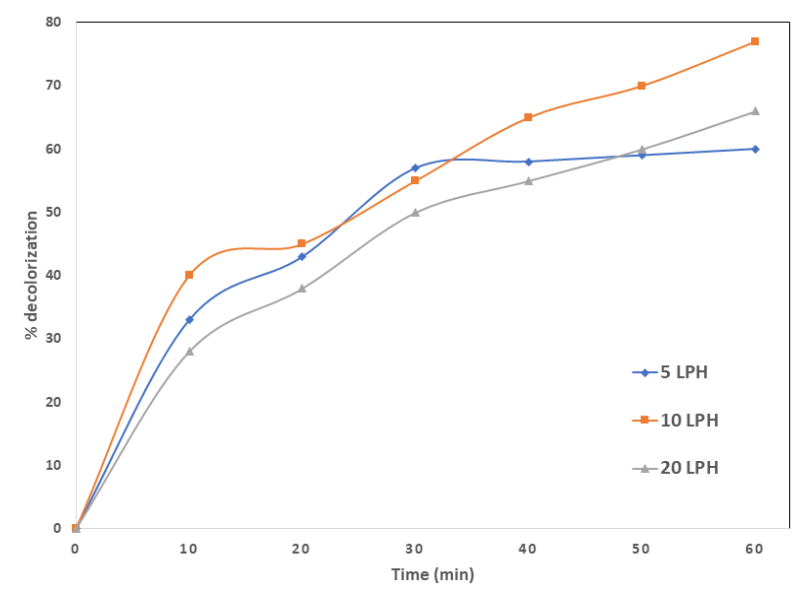

Figure 7. Effect of varying flow rate on MGO dye decolorization (Reaction conditions: $4 \mathrm{~L}$ of dye solution with $100 \mathrm{ppm}$ dye concentration, Light intensity $32 \mathrm{~W}$ and $\mathrm{pH}=3.0$ )

\subsection{Sulphate radical based advanced oxidation processes} (SR-AOPs)

UV irradiation convey energy to per-sulphate anion causing cleavage of per-sulphate bond and producing two sulphate radicals (reaction 13) (Samarghandi et al., 2017). Sulphate radicals react with water at all pHs generating ${ }^{\circ} \mathrm{OH}$ radicals (reaction 14) that are primary reactive 
species under basic conditions (reaction 15). Sulphate radical based AOPs (UV/SO ${ }_{4}^{-\bullet}$ ) may complement common - $\mathrm{OH}$ radicals based AOP technologies $\left(\mathrm{UV} / \mathrm{H}_{2} \mathrm{O}_{2}\right.$ ) (Shokoohi et al., 2017). In order to see the effect of sulphate radicals on decolorization rate of MGO dye, experiments were conducted by varying sodium persulphate concentration from 0.84-3.36 $\mathrm{mM}$ in $\mathrm{UV} / \mathrm{SO}_{4}{ }^{-\bullet}$ process. More than $96 \%$ of decolorization was observed for $1.68 \mathrm{mM}$ of per-sulphate. Beyond $1.68 \mathrm{mM}$, it was decreased due to some side reactions (scavenging effects) (Ike et al., 2018; Hilles and Abu Amar, 2016). The reaction of excess persulphate $(3.36 \mathrm{mM})$ with sulphate radicals may happen with use of persulphate more than the optimum. The rate of decolorization reaction is inhibited because of excess persulphate in solution. It results in the reduction of effectiveness of decolorization for MGO dye.

$$
\mathrm{S}_{2} \mathrm{O}_{8}{ }^{2-}+h v \rightarrow 2 \mathrm{SO}_{4}^{-\bullet}
$$

$\mathrm{SO}_{4}{ }^{-\bullet}+\mathrm{H}_{2} \mathrm{O} \rightarrow \mathrm{SO}_{4}{ }^{2-}+\mathrm{HO}^{\bullet}+\mathrm{H}^{+}$

$\mathrm{SO}_{4}^{-\bullet}+\mathrm{HO}^{-} \rightarrow \mathrm{SO}_{4}{ }^{2-}+\mathrm{HO}^{\bullet}$

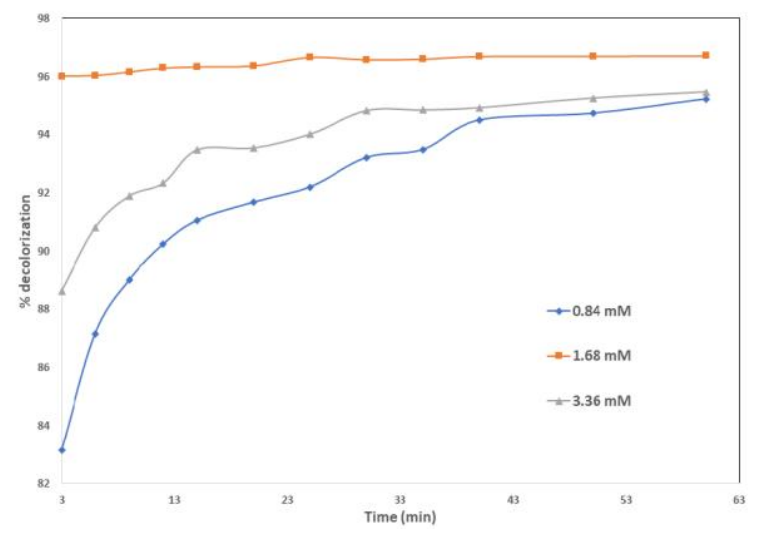

Figure 8. Effect of sulphate radical concentrations on MGO dye decolorization with time (Reaction conditions: $4 \mathrm{~L}$ of $100 \mathrm{ppm}$ dye solution, Flow rate $10 \mathrm{LPH}$, Light intensity $32 \mathrm{~W}$ and

$$
\mathrm{pH}=3.0 \text { ) }
$$

At $\mathrm{pH}<7$, sulphate radicals are dominant reactive species; so, hydroxyl and sulphate radicals are equally participated in reactions at neutral $\mathrm{pH}$. Sulphate radicals are electrophilic, electron-donating groups having faster reaction rates than any other radicals (Samarghandi et al., 2017). Per-sulphate react with organics directly which may produce organic radials (Matzek and Carter, 2016). Figure 8 shows the effect of sulphate radical concentration on dye decolorization at a varying concentration of persulphate.

\subsection{Kinetic study}

Pseudo-first-order reaction kinetics of two different types of Advanced Oxidation Technologies (sulphate and hydroxyl radical based AOPs with irradiation) were studied to calculate their reaction rates. $\mathrm{UV} / \mathrm{SO}_{4}{ }^{-}$and
$\mathrm{UV} / \mathrm{H}_{2} \mathrm{O}_{2}$ processes were compared to study their efficiencies. The parameters of kinetic models for decolorization of $\mathrm{MGO}$ dye at $12 \mathrm{mM}$ of $\mathrm{H}_{2} \mathrm{O}_{2}$ and $1.68 \mathrm{mM}$ per-sulphate concentrations with UV were investigated by applying linear regression analysis to $\left[\ln \left(C_{0} / C_{t}\right)\right.$ versus $\left.t\right]$ data for pseudo-first-order model. Figure 9 indicates the pseudo-first-order reaction kinetics for two different types of AOPs (UV/SO ${ }_{4}^{-\bullet}$ and $\mathrm{UV} / \mathrm{H}_{2} \mathrm{O}_{2}$ processes respectively).

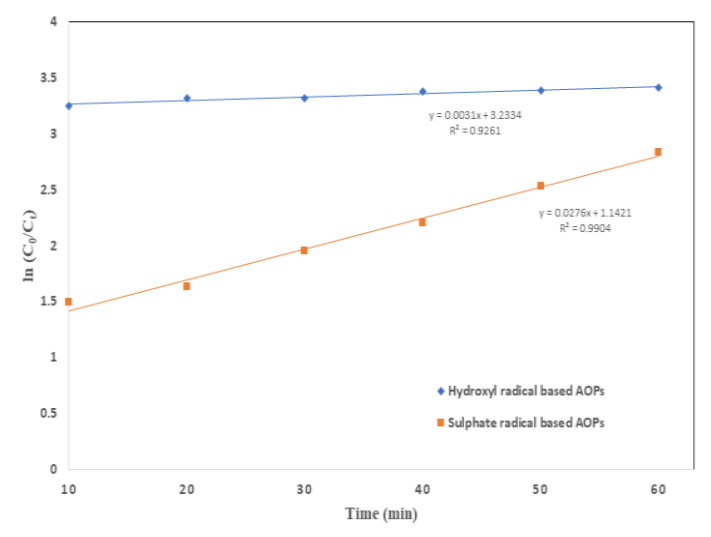

Figure 9. Pseudo-first-order reaction kinetics for two different types of Advanced Oxidation Technologies (Reaction Conditions: [MGO] $]_{0} 100$ ppm, $12 \mathrm{mM}$ of $\mathrm{H}_{2} \mathrm{O}_{2}, 1.68 \mathrm{mM}$ per-sulphate, $\mathrm{pH}$ 3.0, irradiation of $32 \mathrm{~W}$ for $60 \mathrm{~min}$ of reaction time)

Results show that $R^{2}$ values of correlation coefficient for pseudo-first-order model for sulphate radical and hydroxyl radical based AOPs equals to 0.9904 and 0.9261 respectively. Thus, this model might be the best fit to explain decolorization of MGO dye solution. The reaction rate constant values $(k)$ for sulphate radical based $A O P$ (SR-AOP) was $0.0276 \mathrm{~min}^{-1}$, while for hydroxyl radical based AOP (HR-AOP), it was $0.0031 \mathrm{~min}^{-1}$. Results shows that the reaction rate value is more for SR-AOP than the HR-AOP. So, it can be concluded that the rate of decolorization for aqueous MGO dye in SR-AOP process was faster than HR-AOP. For that reason, HR-AOP (UV/SO ${ }_{4}^{-}$process) is more efficient than the HR-AOP (UV/ $\mathrm{H}_{2} \mathrm{O}_{2}$ process) for the decolorization studies of $M G O$ dye in aqueous medium.

\section{Conclusion}

Decolorization of Malachite Green Oxalate dye was carried out with homogeneous [UV, UV/ $\mathrm{H}_{2} \mathrm{O}_{2}$, $\mathrm{UV} / \mathrm{H}_{2} \mathrm{O}_{2} / \mathrm{Fe}^{2+}$ (photo-Fenton process)] and heterogeneous $\left(\mathrm{UV} / \mathrm{TiO}_{2}\right.$ and $\mathrm{UV} / \mathrm{H}_{2} \mathrm{O}_{2} / \mathrm{TiO}_{2}$ ) AOPs. Influence of $\mathrm{Fe}^{2+}$ ions and oxidant $\left(\mathrm{H}_{2} \mathrm{O}_{2}\right)$ concentration and comparison of various Photo-chemical AOPs on the rate of decolorization were studied. The experimental results reveal that:

- Optimum $\mathrm{H}_{2} \mathrm{O}_{2}$ concentration is $12 \mathrm{mM}$ at which maximum \% decolorization of MGO dye was achieved with photo-Fenton process in $60 \mathrm{~min}$ of reaction time.

- Maximum percentage decolorization achieved with $0.6 \mathrm{~g} / \mathrm{L}$ of $\mathrm{TiO}_{2}$ dose in heterogeneous processes where as in Photo-Fenton process 
maximum removal achieved with $60 \mathrm{ppm}$ of $\mathrm{Fe}^{2+}$ ions.

- Percentage dye decolorization occurred the order: Photo-Fenton $>\mathrm{UV} / \mathrm{H}_{2} \mathrm{O}_{2} / \mathrm{TiO}_{2}>\mathrm{UV} / \mathrm{TiO}_{2}>$ $\mathrm{UV} / \mathrm{H}_{2} \mathrm{O}_{2}>$ UV.

- $\quad$ AOP experiments showed that the photochemical oxidation caused by $\mathrm{SO}^{\bullet-}$ radicals in $\mathrm{UV} / \mathrm{SO}_{4}{ }^{\bullet-}$ process is higher than ${ }^{\circ} \mathrm{OH}$ radicals in $\mathrm{UV} / \mathrm{H}_{2} \mathrm{O}_{2}$ process.

- Decolorization of MGO dye solution follows the kinetics of pseudo-first-order model.

\section{Acknowledgments}

We gratefully acknowledge the Department of Chemical Engineering (National Institute of Technology, Raipur) for providing the necessities and required facilities for the success of this work.

\section{References}

Al Momani F., Sans C. and Esplugas S. (2004), A comparative study of the advanced oxidation of 2,4-dichlorophenol, Journal of Hazardous Materials, 107, 123-129.

Abbasi H. and Asgari H. (2018), Removal of methylene blue from aqueous solutions using luffa adsorbent modified with sodium dodecyl sulfate anionic surfactant, Global NEST Journal, 20, 582-588.

Ahmed S.N., Raid T.A.K. and Shreeshivadasan C. (2018), Treatment of Textile Wastewater Using a Novel Electrocoagulation Reactor Design, Global NEST Journal, 20, 449-457.

Aljuboury D.A.D. and Palaniandy P. (2017), Kinetic study of inorganic carbon (IC) removal and COD removal from refinery wastewater by solar Photo-Fenton, Global NEST Journal, 19, 641-649.

Bousnoubra I., Sehili T. and Djebbar K. (2017), Treatment of Bromocresol Purple Dye by Several Photochemical Processes in Aqueous Medium: A Comparative Study, Der Pharma Chemica, 9, 13-17.

Brienza M. and Katsoyiannis I.A. (2017), Sulfate radical technologies as tertiary treatment for the removal of emerging contaminants from wastewater, Sustainability, 9, 1-18.

Dewil R., Mantzavinos D., Poulios I. and Rodrigo M.A. (2017), New perspectives for Advanced Oxidation Processes, Journal of Environmental Management, 195, 93-99.

Elhami V., Karimi A. and Aghbolaghy M. (2015), Preparation of heterogeneous bio-Fenton catalyst for decolorization of Malachite Green, Journal of theTaiwan Institute of Chemical Engineers, 56, 154-159.

Fraiese A., Naddeo V., Uyguner-Demirel C.S., Prado M., Cesaro A., Zarra T., Liu H., Belgiorno V. and Ballesteros Jr. F. (2019), Removal of emerging contaminants in wastewater by sonolysis, photocatalysis and ozonation. Global NEST Journal, 21, 98-105.

Guan Y., Cao W., Guan H., Lei X., Wang X., Tu Y., Marchetti A. and Kong X. (2018), A novel polyalcohol-coated hydroxyapatite for the fast adsorption of organic dyes, Colloids and Surfaces A: Physicochemical and Engineering Aspects, 548, 85-91.
Guimaraes J.R., Maniero M.G. and Nogueira Araujo R. (2012), A comparative study on the degradation of RB-19 dye in an aqueous medium by advanced oxidation processes, Journal of Environmental Management, 110, 33-39.

Garcia C.A. and Hodaifa G. (2017), Real olive oil mill wastewater treatment by photo-Fenton system using artificial ultraviolet light lamps, Journal of Cleaner Production, 162, 743-753.

He K., Chen G., Zeng G., Chen A., Huang Z., Shi J., Huang T., Peng M. and Hu L. (2018), Three-dimensional graphene supported catalysts for organic dyes degradation, Applied Catalysis $B$ : Environmental, 228, 19-28.

Hilles A.H. and Abu Amar S.S. (2016), Factorial design and optimization of leachate treatment using persulfate oxidation, Global NEST Journal, 18, 842-854.

Imoberdorf G. and Mohseni M. (2012), Kinetic study and modeling of the vacuum-UV photoinduced degradation of 2,4-D, Chemical Engineering Journal, 187, 114-122.

Ikel A., Linden K.G. and Duke M. (2018), Critical review of the science and sustainability of persulphate advanced oxidation processes, Chemical Engineering Journal, 338, 651-669.

Jamil T.S., Ghaly M.Y., El-Seesy I.E., Souaya E.R. and Nasr R.A. (2011), A comparative study among different photochemical oxidation processes to enhance the biodegradability of paper mill wastewater, Journal of Hazardous Materials, 185, 353-358.

Li H., Liu S., Zhao J. and Feng N. (2016), Removal of reactive dyes from wastewater assisted with kaolin clay by magnesium hydroxide coagulation process, Colloids and Surfaces $A$ : Physicochemical and Engineering Aspects, 494, 222-227.

Luo S., Gao L., Wei Z., Spinney R., Dionysiou D.D., Hu W.P., Chai L. and Xiao R. (2018), Kinetic and mechanistic aspects of hydroxyl radical-mediated degradation of naproxen and reaction intermediates, Water Research, 137, 233-241.

Lutterbeck C.A., Machado E.L. and Kummerer K. (2015), Photodegradation of the antineoplastic cyclophosphamide: A comparative study of the efficiencies of $\mathrm{UV} / \mathrm{H}_{2} \mathrm{O}_{2}$, $\mathrm{UV} / \mathrm{Fe}^{2+} / \mathrm{H}_{2} \mathrm{O}_{2}$ and $\mathrm{UV} / \mathrm{TiO}_{2}$ processes, Chemosphere, 20, 538-546.

Macawile M.C., Centeno C. and Abella L.(2011), Effect of Light Intensity on the Photodegradation of $\mathrm{PCB} 153$ in Aqueous Solution using UV and $\mathrm{UV} / \mathrm{H}_{2} \mathrm{O}_{2}$, Journal of Water and Environment Technology, 9, 69-77.

Matzek L.W. and Carter K.E. (2016), Activated persulfate for organic chemical degradation: A review, Chemosphere, 151, 178-188.

Maiti S., Sinha S.S. and Singh M. (2017), Microbial decolorization and detoxification of emerging environmental pollutant: Cosmetic hair dyes, Journal of Hazardous Materials, 338, 356-363.

Moreira A.J., Borges A.C., Gouvea L.F.C., MacLeod T.C.O. and Freschi G.P.G. (2017), The process of atrazine degradation, its mechanism, and the formation of metabolites using UV and UV/MW photolysis,Journal of Photochemistry and Photobiology A: Chemistry, 347, 160-167.

Martorell M.M., Pajot H.F. and Figueroa L.I.C. (2017), Biological degradation of Reactive Black 5 dye by yeast Trichosporon akiyoshidainum, Journal of Environmental Chemical Engineering, 5, 5987-5993.

Ortega-Liebana M.C., Sanchez-Lopez E., Hidalgo-Carrillo J., Marinas A., Marinas J.M. and Urbano F.J. (2012), A comparative study of photocatalytic degradation of 3- 
chloropyridine under UV and solar light by homogeneous (photo-Fenton) and heterogeneous $\left(\mathrm{TiO}_{2}\right)$ photocatalysis, Applied Catalysis B: Environmental, 127, 316-322.

Ratna P.B.S. (2012), Pollution due to synthetic dyes toxicity and carcinogenicity studies and remediation, International Journal of Environmental Sciences, 3, 940-955.

Rajoriya S., Bargole S., George S. and Saharan V.K. (2018), Treatment of textile dyeing industry effluent using hydrodynamic cavitation in combination with advanced oxidation reagents, Journal of Hazardous Materials, 344, 1109-1115.

Raval N.P., Shah P.U. and Shah N.K. (2016), Malachite green 'a cationic dye' and its removal from aqueous solution by adsorption, Applied Water Science, 7, 3407-3445.

Rahim Pouran S., Abdul Aziz A.R. and Wan Daud W.M.A. (2015), Review on the main advances in photo-Fenton oxidation system for recalcitrant wastewaters, Journal of Industrial and Engineering Chemistry, 21, 53-69.

Sarkheil H., Noormohammadi F., Rezaei A.R. and Borujeni M.K. (2014), Dye Pollution Removal from Mining and Industrial Wastewaters using Chitson Nanoparticles, International Conference on Agriculture, Environment and Biological Sciences (ICFAE'14), June 4-5, Antalya (Turkey).

Samarghandi M.R., Mehralipour J., Azarian G., Godini K. and Shabanlo A. (2017), Decomposition of sodium dodecylbenzene sulfonate surfactant by Electro/ $\mathrm{Fe}^{2+}$ activated persulfate process from aqueous solutions, Global NEST Journal, 19, 115-121.

Shanmugam S., Ulaganathan P., Swaminathan K., Sadhasivam S. and Wu Y.R. (2017), Enhanced biodegradation and detoxification of malachite green by Trichoderma asperellum laccase: Degradation pathway and product analysis, International Biodeterioration \& Biodegradation, 125, 258268.

Shokoohi R., Shabanloo A.,Vanaei M. and Torkshavand Z. (2017), Response surface methodological approach for optimizing removal of ciprofloxacin from aqueous solution using thermally activated persulfate/aeration systems, Global NEST Journal, 19, 389-395.

Shankaraiah G., Saritha P., Bhagawan D., Himabindu V. and Vidyavathi S. (2017), Photochemical oxidation of antibiotic gemifloxacin in aqueous solutions - A comparative study, South African Journal of Chemical Engineering, 24, 8-16.

Samarghandi M.R., Rahmani A., Asgari G., Ahmadidoost G. and Dargahi A. (2018), Photocatalytic removal of cefazolin from aqueous solution prepared from mango seed $+\mathrm{ZnO}$ under UV irradiation AC, Global NEST Journal, 20, 399-407.

Vikranta K., Giria B.S., Raza N., Roya K., Kim K.H., Rai B.N. and Singha R.S. (2018), Recent advancements in bioremediation of dye: Current status and challenges, Bioresource Technology, 253, 355-367.

Vaid F.H.M., Zahid S., Faiyaz A., Qadeer K., Gul W., Anwar Z. and Ahmad I. (2018), Photolysis of methylcobalamin in aqueous solution: A kinetic study, Journal of Photochemistry and Photobiology A: Chemistry, 362, 40-48.

Villegas-Guzman P., Silva-Agredo J., Florez O., Giraldo-Aguirre A.L., Pulgarin C. and Torres-Palma R.A. (2017), Selecting the best AOP for isoxazolyl penicillins degradation as a function of water characteristics: Effects of $\mathrm{pH}$, chemical nature of additives and pollutant concentration, Journal of Environmental Management, 190, 72-79.
Xiao X., Li T., Lu X., Feng X., Han X., Li W., Li Q. and Yu H. (2018), A simple method for assaying anaerobic biodegradation of dyes, Bioresource Technology, 251, 204-209. 